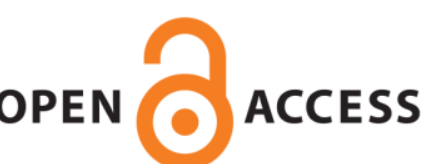

UWS Academic Portal

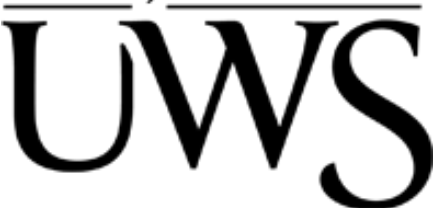

\title{
Use of a mnemonic to support suicide intervention training for nursing students
}

Gillespie, Mark

Published in:

Mental Health Practice

DOI:

10.7748/mhp.2019.e1424

Published: 09/01/2020

Document Version

Peer reviewed version

Link to publication on the UWS Academic Portal

Citation for published version (APA):

Gillespie, M. (2020). Use of a mnemonic to support suicide intervention training for nursing students. Mental Health Practice, 23(1). https://doi.org/10.7748/mhp.2019.e1424

\section{General rights}

Copyright and moral rights for the publications made accessible in the UWS Academic Portal are retained by the authors and/or other copyright owners and it is a condition of accessing publications that users recognise and abide by the legal requirements associated with these rights.

Take down policy

If you believe that this document breaches copyright please contact pure@uws.ac.uk providing details, and we will remove access to the work immediately and investigate your claim. 
A mnemonic to support the assessment and management of suicide risk

\section{Abstract}

Suicide is a global problem that is currently attracting significant focus. Within the U.K. the reduction of deaths caused by suicide is a goal for each of the home nations and has led to the development of initiatives enhancing training on the recognition and management of suicide risk. Many of the groups associated with heightened risk of suicide are in contact with health services and as a result nurses will frequently encounter people who are suicidal. This is recognised within the recently updated NMC proficiencies for nurse education which mandates proficiency in suicide risk management for nurses qualifying within all fields of nursing. As part of a review of suicide intervention training one university developed the TIPTOES mnemonic to support student nurses gradually develop confidence and competence in suicide intervention.

Keywords

Suicide; suicide intervention; nurse education; mental health nursing

Introduction

The recent revamp of NHS Education for Scotland's (2019) resources to support the development of suicide prevention skills highlights the need for ongoing improvement in how people working with individuals at risk of suicide are prepared and supported to manage that risk. Suicide intervention training is integral within pre-registration nursing programmes, though evidence suggests that nurses often struggle with this issue in practice. This paper identifies how a mnemonic introduced alongside existing training packages may help students remember and understand key steps of the intervention process. The wider applicability of the mnemonic is also discussed.

Suicide intervention

The World Health Organization's (WHO) inaugural mental health action plan emphasised the need for improvement in the recognition and management of suicide (WHO, 2014). This was evidence of a growing awareness of the extent of suicide as a global problem, with around 800,000 people each year dying as a result of suicide worldwide (WHO, 2018), and just under six thousand people identified as completing suicide in just one year in the U.K. (Samaritans, 2019). This awareness has led to a political focus on suicide prevention planning within the U.K., and to the development of policy guidance and practice development recommendations for health and social care delivery in each of the home nations (Mackley, 2018). 
The most obvious goal of related U.K. policy is the reduction in deaths attributed to suicide. In Scotland the plan is to reduce suicide by $20 \%$ by 2022 (Scottish Government, 2018) and England aims for a 10\% reduction by 2021 (HM Government, 2017). Wales sets no specific numerical target, emphasising instead a general reduction in the number of suicides (Welsh Government, 2015) and Northern Ireland follows suit in its recent draft policy review. This review is currently waiting to be implemented as a result of the current impasse on the formation of a government there (Mackley, 2018). Each of these suicide reduction goals are supported by proposals for service redevelopment and the enhancement of training for professional groups who are either associated with high risk populations or who engage with the public at key points.

Many of the at-risk groups for suicide are in contact with health services and as a result are frequently cared for by nurses. Noonan (2018) identifies such individuals as including people being treated for, or who have previously been treated for mental ill health, people who abuse substances, people who have physical illness and people who self-harm. Nurses, and in particular mental health nurses, therefore, are frequently involved with persons at risk of suicide, and this contact often occurs at times of crisis for those individuals. The National Confidential Inquiry into Suicide and Safety in Mental Health (Healthcare Quality Improvement Partnership (HQIP), 2018) indicates that while improvements have been made in reducing the number of suicides amongst those in contact with mental health services, this population still constitutes around a third of the overall total of suicides in the U.K.

The improvements in overall suicide rates evidenced by the HQIP would suggest that the prevention initiatives and educational developments adopted have been at least partially successful. The recently published proficiencies expected of nurses at their point of registration includes the ability to assess and manage suicide risk (Nursing and Midwifery Council (NMC), 2018), meaning all newly qualified nurses completing programmes incorporating these new standards will have a baseline of knowledge and skills to support suicide prevention. Post registration training is available in various guises and both pre-registration and registered nurses can access internationally standardised training packages such as safeTALK and Applied Suicide Intervention Skills Training (ASIST), both developed and managed by Livingworks (Livingworks, n.d.), an organisation based in Canada, and STORM (STORM, n.d) a U.K. based intervention. These interventions incorporate a mix of theory, practise and feedback and pre-registration nurse training often includes a combination of these approaches or similar locally developed initiatives to gradually increase the ability of students to manage suicide risk across their programme. Despite these training opportunities suicide remains an issue of concern with over 1600 health service patients completing suicide in 2016 (HQIP, 2018) 
and evidence suggesting that healthcare professionals often lack confidence in their ability to assess and manage suicide risk (Mirik et al, 2016).

With nurses in all fields of practice now being required to develop proficiency in suicide identification, assessment and management by their point of registration (NMC, 2018) there is a need to review the related educational content within preparatory pre-registration programmes. This is also true for post registration education, especially for registrants in the adult and child fields for whom the previous NMC standards did not specifically identify this competence as a mandatory requirement (NMC, 2010). There have been widespread calls for enhancement of the educational preparation and training for nurses in the area of suicide prevention (Bethel, 2013; O'Donnell, 2012) with completion of such courses having been found effective in supporting suicide reduction initiatives (Calear et al, 2016). The recent addition of these proficiencies to the pre-registration curriculum supports current review of how such education is delivered.

Learning to manage suicide risk can be a daunting prospect, though is of vital importance. When nurses lack knowledge of suicide prevention and the skills required to implement it there can be traumatic and even fatal consequences for patients (Bolster et al, 2015). Thomas (2017) identifies that nurses often feel underprepared to engage in suicide intervention. This suggests that there would be a strong desire for any educational preparation supporting the development of these capabilities. This, though, does not always appear to be the case. Barriers to engaging nurses in suicide prevention have been identified in several studies across various fields of nursing specialisms. Fry (2012) for example raises the issue of responsibility, highlighting some nurses reluctance to engage in managing suicide because of perceived limitations of their job role or through concerns around their own inexperience. Couillet et al (2017) found that some nurses avoided involvement in suicide intervention as they saw it as a patient choice matter. Bolster et al (2015), meanwhile, identify the cultural background of nurses as a possible issue, with some nurses holding culture driven attitudes to suicide that encouraged them to lack empathy, or even be hostile towards those who were suicidal. Educational programmes shaped to develop suicide prevention skills for nurses therefore need to be robust enough to overcome such inherent difficulties and sufficiently practice focused to be applicable in the clinical setting. In one university, responsible for the delivery of pre-registration nurse education, this led to the development of a mnemonic to support suicide intervention training (Box 1 ).

Add box 1 here

Mnemonics 
Mnemonics are memory retrieval techniques that help connect new learning to existing knowledge (Fontana et al, 2007). Their use is suggested to promote learners to more deeply consider an issue as opposed to simply act automatically towards it (Billings and Kowalski, 2005). This is ideal for learning suicide prevention skills as there are a set of key areas that need to be addressed within every intervention, though adapting the approach to accommodate the individual nature of suicidal experience for patients requires mental flexibility from the practitioner involved. This mnemonic was developed primarily to help pre-registration nursing students remember the key issues to be addressed within a suicide intervention strategy, though it may be of use to registered nurses and other healthcare professionals as well for the same reason. When learning suicide intervention techniques it is important that practitioners get the opportunity to test new knowledge through applying it in simulated practice settings before using it in real situations (Mirik et al, 2016). The mnemonic is therefore only one component of a wider learning strategy for suicide intervention based on social constructivist learning theory.

Constructivist learning theory recognises the student as an active participant in the educational process, whose learning is shaped by their own individual experience and perspectives (Glance et al, 2018). Social constructivism meanwhile emphasises the role of interaction between the student and others in the development of learning and identifies the importance of learning experiences occurring within situations or environments that are salient to the targeted subject or skills (Schreiber and Valle, 2013). Scaffolding is a key approach associated with social constructivist learning which involves the development of supports that assist the learner to gradually develop independent mastery (Malik and Wiseman, 2017). The mnemonic is used within the scaffolding process and supports the student to develop proficiency in suicide intervention in a safe and supported manner. This learning occurs across the students programme and incorporates gradually increasing complexity of involvement in suicide intervention. Initial student feedback has been positive with comments emphasising the mnemonics usefulness in prompting recall of key stages within the suicide intervention process. A more formal evaluation of the approach is planned. Each of the components of the mnemonic is drawn from contemporary research and the shared content of widely used suicide intervention training packages. The author of this article is an ASIST master trainer, and a qualified and experienced trainer in safeTALK and STORM. The incorporation of the concepts underpinning these interventions in our overall training approach is important as nurses involved in suicide interventions are extremely likely to need to engage with other practitioners within this process. To ensure a cohesive approach each training programme should therefore aim to fit with suicide intervention preparation delivered elsewhere. The introduction of the mnemonic provides a bridge for students, linking the key processes included in each of the 
suicide prevention training initiatives undertaken across their programme. A rationale for the content of the mnemonic is detailed below.

\section{Trauma}

Trauma is associated in a number of ways with an increased risk of suicide. Within the mnemonic it is used as a prompt to highlight what factors a practitioner should be looking for to alert them to the fact that suicide may be an issue for the patient in question. The association between various forms of trauma and increased suicide risk has been long established with Duffy and Ryan (2004) highlighting the role of stressors such as bereavement, substance misuse, experiences of abuse, financial, legal and relationship difficulties, unemployment and physical and mental ill health all background factors to be considered. Current experience of a traumatic event appears to heighten risk with recent exposure to adverse life events highlighted as a concern (Gordon et al, 2017) In addition to traumatic experiences Noonan (2018) also recommends review of the individual's current presentation including their mood and any sense of hopelessness expressed.

\section{Intent}

If there are features associated with the patient that raise the practitioners concerns around suicide the most effective way to explore this is to check whether the patient has any thoughts of suicide or any intention to engage in suicidal behaviour. Noonan (2018) highlights the need to fully assess suicidal intent. To achieve this Fry (2012) encourages the benefits of asking the patient directly and clearly about suicide, indicating that the use of a phrase such as "are you thinking of killing yourself, of suicide?" ensures agreement that suicide is indeed the issue that needs addressed. This question should be posed sensitively and contextualised using the factors that raise the nurses concern; "you seem to have lost hope" would be an example of such a preparatory phrase. The level of intent should be further explored in regards the intensity, frequency and nature of the individuals thoughts of suicide and their attitude and demeanour towards such thoughts. This discussion should also include time and space for the person to identify the reasons for their current dilemma.

\section{Plan and Timing}

A key issue in ascertaining a sense of the level of risk for an individual experiencing suicidal thoughts is the form and detail of any plan they have formulated to carry this out (Bethel, 2013). Vidabeck (2009) indicates that understanding the extent of the persons planning will provide an indication of the present level of risk. Understanding the plan will also identify how the plan could be disabled, and removal of the potential means of suicide is an important aspect of prevention (Noonan, 2018). The exploration of any plans made by the person at risk should include consideration of the 
immediacy of their intentions. This gives indication of the timeframe within which any intervention can be introduced. Understanding the timeframe involved, therefore, is of crucial importance.

\section{Other experience if suicide}

One of the risk factors for suicide is prior suicidal experience (Noonan, 2018). Familiarity with suicidal behaviour (and self-harm) makes further attempts more likely and also provides the individual with an understanding of what doesn't work, potentially increasing the lethality of the next method chosen. Prior suicidal experience alternately allows discussion of what coping strategies and supports have been effective in maintaining the individual since their last attempt. Discussion around this should explore the detail of any coping strategies that emerged for them following previous attempts, and any services they engaged with for help as a consequence. All of which is useful when formulating a plan for intervention.

\section{Encouragements}

An important step in suicide prevention is identification of the individual's reasons for living (Wang et al, 2013). Aspects of the person's life, including people important to them, are often encouragements that can be emphasised in negotiating agreement for the need for help. Helping the person identify a more realistic understanding of the balance of positives and negatives in their lives may influence that individual to seek support and see that suicide is not the only alternative available to them.

\section{Support}

It would be hoped that as such discussion unfolds, the person involved would gradually understand their level of risk and become more accepting of the value of support. Whether this occurs or not the practitioner now needs to focus their thoughts, and the conversation, towards what supports are going to be required to help protect this person's life. When people are at immediate and significant risk of suicide this means a response that is reflective of the extent of the threat. For nurses on duty this may mean review of the persons observation levels or assessment by a specialist service if the person is an in-patient. For community based patients this may mean involving emergency services, crisis teams or consideration of hospital admission.

For people having infrequent thoughts of suicide that they have no intention of acting on such a response is obviously inappropriate and they may only require being linked with a telephone crisis service. Nurses, therefore, need to know what supports are available within their community, and be able to make sound clinical, evidence based judgements about the nature and timing of supports required for each individual presentation. NICE (2018) recognise the need for a multi- agency 
approach to suicide prevention at a strategic level and this partnership approach to suicide intervention is equally preferred for individual interventions. Risk assessment decisions should be arrived at or confirmed through discussion with the practitioner's clinical team or subject experts where appropriate. The nurse directly involved in the interventions though will likely need to negotiate the involvement of supports with the patient involved, sometimes against that persons wishes. Risk assessment tools are available to aid clinical decision making though it should be emphasised that such frameworks should assist with this process, not drive it (Scottish Executive Health Department, 2000).

Summary and conclusion

Suicide intervention is a responsibility that all nurses should feel able to take on. Training and ongoing support is required to make this a reality and the recently updated NMC standards for nurse education supports the development of new initiatives to help nurses in all fields develop suicide intervention skills. The use of the TIPTOES mnemonic will help students and possibly registered nurses, and other healthcare professionals remember the key components of a suicide prevention intervention, supporting them to develop confidence as they gradually master the interpersonal skills and process of a suicide intervention. It should be noted that the mnemonic is only an aid to the recall and understanding of the key components of suicide intervention and the development of competence in this process will require wider training, practice, mentoring and clinical supervision. The mnemonic was initially designed as a prompt to encourage recall and wider consideration in student mental health nurses learning suicide intervention through engagement in training initiatives that spanned their programme. It seems likely however that recently published NMC directives suggest it would now be as relevant for student nurses in other fields, and feedback from students already using the approach have highlighted its possible relevance for other healthcare professionals. The brief though attention catching nature of the mnemonic is also likely to raise interest and awareness in individuals for whom suicide intervention is an infrequent, though possible element of their job role.

References

Bethel, J (2013) Assessment of suicidal intent in emergency care. Nursing Standard. 28 (4). 52-58. Billings, D and Kowalski, K (2005) Do Your CATS PRRR?: A Mnemonic Device to Teach Safety Checks for Administering Intravenous Medications The Journal of Continuing Education in Nursing • May/June $2005 \cdot$ Vol 36, No 3. 104-106.

Bolster, C. Holliday, C. O'Neal, G and Shaw, M (2015) Suicide assessment and nurses: what does the evidence show? Journal of Online Nursing Issues. 10913734, 20 (1). 
Calear, A. L. Christense, H. Freeman, A. Fenton, K. Busby-Grant, J. van Spijker, B and Donker, T (2016) A systematic review of psychosocial suicide prevention interventions for youth. European Child Adolescent Psychiatry. 25. 467-482.

Couillet, A. Terra, J. Brochard, N and Chauliac, N (2017) Barriers to the Prevention of Suicide in Nursing Homes A Qualitative Study of the Social Representations of Caregivers. Crisis (2017), 38(6), 423-432 DOI: 10.1027/0227-5910/

Duffy, D and Ryan, T (2004) New approaches to preventing suicide; a manual for practitioners. London. Jessica Kingsley Publishers.

Fontana, J. L. Scruggs, T and Mastropieri, M. A (2007) Mnemonic Strategy Instruction in Inclusive Secondary Social Studies Classes. Remedial and special education. 345 Volume 28, Number 6, November/December 2007, 345-355

Fry, J (2012) Suicide awareness and prevention training in a high security setting. Mental Health Practice. 15 (6). 25-31.

Glance, D. Rhinehart, A and Brown, A (2018) Learn, expand, engage: A model for teaching clinical skills in the helping professions. Adult Learning. 29 (3). 104-114.

Gordon,V. James, K. Janner, M. Windfuhr, K and Hunt, I. M (2017) Suicide. In; Chambers (Ed) Psychiatric and mental health nursing (third Edition). Abingdon. Routledge.

Healthcare Quality Improvement Partnership (2018) The National Confidential Inquiry into Suicide and Safety in Mental Health; annual report; England, Northern Ireland, Scotland, Wales.

HM Government (2017) Preventing suicide in England; third progress report of the crossgovernment outcomes strategy to save lives. [Online] Retrieved from https://www.gov.uk/government/publications/suicide-prevention-third-annual-report Accessed 28/5/19

Livingworks (n.d.) Homepage [Online]. Retrieved from https://www.livingworks.net/ Accessed $27 / 5 / 19$

Mackley, A (2018) Suicide prevention: policy and strategy (briefing paper). [Online] Retrieved from https://researchbriefings.parliament.uk/ResearchBriefing/Summary/CBP-8221 Accessed 28/5/19

Malik, S. A and Wiseman, A. W (Reviewing Editor) (2017) Revisiting and re-representing scaffolding: The two gradient model, Cogent Education, 4:1, DOI: 10.1080/2331186X.2017.1331533

Mirik, R. McCauley, J. Bridger, J and Berkowitz, L (2016) Continuing education on suicide assessment and crisis intervention: what can we do about the needs of mental health professionals in community practice? Community Mental Health Journal. 52. 501-510.

National Institute for Health and Care Excellence (2018) Preventing suicide in community and custodial settings. [Online] retrieved from https://www.nice.org.uk/guidance/ng105 Accessed $28 / 5 / 19$

NHS Education for Scotland (2019) Ask, Tell- save a Life; Every life matters. [Online] Retrieved from https://vimeo.com/338176393 Accessed 29/5/19

Noonan, I.P.S (2018) Assessing and managing the risk of self-harm and suicide. In; Norman and Ryrie (Eds) The art and science of mental health nursing $\left(4^{\text {th }} \mathrm{Edn}\right)$. London. Open University Press. 
Nursing and Midwifery Council (2010) Standards for pre-registration nursing education. [Online] retrieved from https://www.nmc.org.uk/globalassets/sitedocuments/standards/nmc-standards-forpre-registration-nursing-education.pdf Retrieved 14/3/19

Nursing and Midwifery Council (2018) Future nurse: standards of proficiency for registered nurses. [Online] Retrieved from https://www.nmc.org.uk/globalassets/sitedocuments/educationstandards/future-nurse-proficiencies.pdf Accessed 13/3/19

O’Donnell, H (2012) Prevention of suicide in Northern Ireland. Mental Health Practice. 15 (8). 25- 29.

Samaritans (2019) Suicide facts and figures. [Online] retrieved from

https://www.samaritans.org/about-us/our-research/facts-and-figures-about-suicide Accessed $\underline{11 / 3 / 19}$

Scottish Executive Health Department (2000) Mental Health Reference Group; Risk Management. [Online] Retrieved from https://www.sehd.scot.nhs.uk/publications/mhrg/mhrg.pdf Accessed $25 / 3 / 19$

Scottish Government (2018) Scotland's suicide prevention action plan; every life matters. [Online] Retrieved from https://www.gov.scot/publications/scotlands-suicide-prevention-action-plan-lifematters/

Schreiber, L. M and Valle, B. E (2013) Social constructivist teaching strategies in the small group classroom. Small Group Research. 44 (4). 395-411.

STORM (n.d.) Skills training. [Online]. Retrieved from https://www.stormskillstraining.com/ Accessed $27 / 5 / 19$

Thomas, L (2017) Nursing children and young people: what mental health training is required? British Journal of Nursing, 2017, Vol 26 (4). 234-237.

Vidabeck, S. L (2009) mental Health Nursing. Philadelphia. Wolters Kluwer health.

Wang, M. Lightsey, O,R. Tran, K. K and Bonaparte, T. S (2013) Examining suicide protective factors among black college students. Death Studies (37). 228- 247.

Welsh Government (2015) Talk to me 2; suicide and self-harm prevention strategy for Wales 20152020. [Online] Retrieved from https://gov.wales/docs/dhss/publications/150716strategyen.pdf Accessed 11/3/19

World Health Organization (2014) Preventing suicide; a global imperative. [Online] Retrieved from https://apps.who.int/iris/bitstream/handle/10665/131056/9789241564779 eng.pdf;jsessionid=B13 1D16252AD79D50BB524629944A4FE?sequence=1 Accessed 7/3/19

World Health Organization (2018) National suicide prevention strategies: progress, examples and indicators [Online] Retrieved from https://www.who.int/mental health/suicide-

prevention/national strategies 2019/en/ Accessed 25/5/19 
TIPTOES- stretch yourself to help someone at risk.

\begin{tabular}{|l|l|}
\hline $\mathrm{T}$ & $\begin{array}{l}\text { Trauma- any recent life changes that have potentiated crisis, substance use or } \\
\text { emotional turmoil indicating heightened risk }\end{array}$ \\
\hline $\mathrm{I}$ & Intent- is the person considering suicide and if so how strong is their intention to do it? \\
\hline $\mathrm{P}$ & Plan- do they have a plan to carry this out and if so what is it exactly? \\
\hline $\mathrm{T}$ & $\begin{array}{l}\text { Timeframe- when are they planning this and how immediate does our response need } \\
\text { to be? }\end{array}$ \\
\hline $\mathrm{O}$ & $\begin{array}{l}\text { Other experience of suicide-what is the persons history in relation to thoughts or } \\
\text { actions around suicide and what learning can we take from this? }\end{array}$ \\
\hline $\mathrm{E}$ & $\begin{array}{l}\text { Encouragement- what encouragements are there that suggest protection against } \\
\text { suicide- supports available/ beliefs/ future plans? }\end{array}$ \\
\hline $\mathrm{S}$ & Support recovery- what now needs done to ensure the person can recover from this? \\
\hline
\end{tabular}

Box 1 Mnemonic 